\title{
Risk programming analysis with imperfect information
}

\author{
Gudbrand Lien · J. Brian Hardaker • \\ Marcel A.P.M. van Asseldonk · James W. Richardson
}

Published online: 12 June 2009

(C) The Author(s) 2009. This article is published with open access at Springerlink.com

\begin{abstract}
A Monte Carlo procedure is used to demonstrate the dangers of basing (farm) risk programming on only a few states of nature and to study the impact of applying alternative risk programming methods. Two risk programming formulations are considered, namely mean-variance $(\mathrm{E}, \mathrm{V})$ programming and utility efficient (UE) programming. For the particular example of a Norwegian mixed livestock and crop farm, the programming solution is unstable with few states, although the cost of picking a sub-optimal plan declines with increases in number of states. Comparing the E,V results with the UE results shows that there were few discrepancies between the two and the differences which do occur are mainly trivial, thus both methods gave unreliable results in cases with small samples.
\end{abstract}

Keywords Quadratic risk programming $\cdot$ States of nature $\cdot$ Sparse data $\cdot$ Kernel smoothing

G. Lien

Lillehammer University College and Norwegian Agricultural Economics Research Institute,

P.O. Box 8024 Dep., 0030 Oslo, Norway

e-mail: gudbrand.lien@hil.no

J.B. Hardaker

School of Business, Economics and Public Policy, University of New England, Armidale, NSW 2351,

Australia

e-mail: bhardake@une.edu.au

M.A.P.M. van Asseldonk ( $\square)$

Agricultural Economics Research Institute, Wageningen University and Research Centre,

P.O. Box 8130, NL $6706 \mathrm{KN}$ Wageningen, The Netherlands

e-mail: marcel.vanasseldonk@wur.nl

J.W. Richardson

Department of Agricultural Economics, Texas A\&M University, College Station, TX 77843-2124, USA

e-mail: jwrichardson@tamu.edu 


\section{Introduction}

There are many reported studies of risk programming for farm planning. Such analyses may be performed to support a decision by an individual farmer about what farm plan to follow next year, i.e., what areas of each crop to plant and what numbers of various types of livestock to run (e.g., Olson and Eidman 1992; Epplin and Al-Sakkaf 1995; Pannell and Nordblom 1998), or they may be undertaken to evaluate some proposed innovation such as a new technology or new policy instrument such as crop insurance (e.g., Krause et al. 1990; Dorward 1999; Lien and Hardaker 2001; Torkamani 2005). The farm-level planning problem addressed is typically assumed to be a short-term decision in that the farmer can change to a different plan in the following year, if appropriate. However, models may also account for sequential or dynamic decision making, as when planning for perennial crops.

For studies which recognise that risk is inevitably important in such choices and that most farmers are risk averse, the analysis will necessarily be cast in terms of some measure of risk efficiency of the alternative choices being compared. Uncertainty may be recognised in the model only in the activity net revenues (yields and prices), or in the constraints, or both. In what follows we focus on the former, although similar considerations will apply to methods commonly used to handle uncertainty in the constraints.

Many different models have been used for the farm planning problem outlined above, with mathematical programming predominating. The form of such programming models ranges from quadratic (E,V) risk programming (Markowitz 1952; Freund 1956) through various linear approximations, such as MOTAD or Target MOTAD (Hazell 1971; Tauer 1983), and various goal programming formulations (e.g., Romero 2000), to direct maximization of expected utility via nonlinear programming, herein called utility efficient (UE) programming (Lambert and McCarl 1985; Patten et al. 1988). These various methods may be applied to both one-stage and multi-stage formulations.

In applications of most of these models it is usual to find that the risk and stochastic dependency among per unit activity net revenues is based on very sparse data. The reason is that, in practice, the historical data for the farm being analysed are often sparse and incomplete, or, when the records exist for many previous years, the relevance of the older information to planning for the future is judged to be low.

Several studies have looked at the reliability of estimated optimal farm plans derived using E,V risk programming based on sparse data, (e.g., Chalfant et al. 1990; Lence and Hayes 1995) and the confidence regions in the mean-standard deviation space (e.g., Collender 1989). Unsurprisingly, all these studies demonstrate that sparse data reduce the reliability of the risk programming results. A similar conclusion was reached by Hardaker et al. (2007) for a UE model. But few studies have compared the vulnerability of different risk programming models such as E,V and UE, to sampling bias (imperfect information).

We assume that there exists a representation of the risks for activity returns, specified by a states of nature matrix which shows the state-contingent values of activity per unit net revenues (gross margins) with associated probabilities for a finite number of states. Since we assume that the aim is to maximise expected utility based on a risk-averse and therefore nonlinear utility function for the farmer, we drop from consideration models such as MOTAD and Target MOTAD. These linear approximations to the nonlinear optimisation are made less relevant by the ready availability of software for nonlinear programming. Hence we focus on a comparison of $\mathrm{UE}$ and $\mathrm{E}, \mathrm{V}$ models. In the former, the risk is represented by direct incorporation of the states of nature matrix into the MP model. Then expected utility is maximised over the specified discrete number of states. No assumptions are made about the 
distributional forms of activity gross margins and net income beyond what are implicit in the states of nature matrix (Lambert and McCarl 1985; Patten et al. 1988). In these models we 'let the data speak'. In the case of E,V models, it is assumed that the risk in activity returns is adequately represented by the means of activity per unit net revenues along with an associated covariance matrix, both calculated from the states of nature matrix (Markowitz 1952; Freund 1956). Implicitly, therefore, higher order moments such as skewness in returns are ignored; in effect, it is assumed that the distribution of activity net revenues is multinormal.

Because of the inability to account for higher moments of net income distribution using $\mathrm{E}, \mathrm{V}$ programming, we might expect it to give less reliable results than UE programming with very many states of nature available, at least if the data are not multinormal distributed. Moreover, because some crop yields have been found not to be normally distributed (Just and Weninger 1999; Atwood et al. 2003), we might expect crop net revenue not to be distributed normally. However, when only few states are available, as is usual, the distributions may be more or less randomly represented, so there is no a-priori reason to assume that one model is superior to the other.

In this paper we used Monte Carlo methods to supplement sparse data and subsequently compare the reliability of solutions obtained by E,V and UE programming. We explore this problem by illustrating the possible bias for a typical Norwegian mixed farm.

\section{Approaches to characterising uncertainty in farm planning models with sparse data}

\subsection{Small sample bias}

Given a time series of historical activity yields, prices and variable costs it can be argued that it is wise to make some adjustments to these data to make them more relevant to the uncertainty in the future planning period. This could entail a variety of adjustments, such as de-trending for inflation, technological or climate change; incorporation of price or weather forecasts; or more subjective revisions based on the beliefs about the future of the decision maker or the analyst. For the purposes of this paper we leave aside questions of how best to make such adjustments.

The question then is how to proceed with a risk programming model making use of the sparse basic data, adjusted or not? Options include:

1. Using the small number of states of activity net revenues-typically gross margins (GMs) - reflected in the historical data directly in the programming model. Direct maximization of expected utility via nonlinear programming is then often the most appropriate model to apply (e.g., Kobzar et al. 2005; Torkamani 2005; Flaten and Lien 2007). It is usual, but not necessarily best, to assume that the states are equi-probable. A drawback with this approach is that the historical information at best represents just one sample from the infinite set of possible futures. Moreover, as noted, the sample size is typically small, meaning that the results must be vulnerable to sampling bias-the issue addressed below.

2. Using the small sample to calculate means and a covariance matrix of activity per unit GMs for E,V analysis via quadratic risk programming (applied by, e.g., Freund 1956; Ames et al. 1993; Bhende and Venkataram 1994). The method is strictly legitimate, as stated before, only under assumptions that the activity returns are multinormal and that the utility function is negative exponential (or, less plausibly, that the utility function is quadratic), although the method is often assumed to be a reasonable approximation even when the multinormal assumption does not hold. More to the point, given that the 
activity means, variances and covariances for E, $\mathrm{V}$ analysis are obtained from the same short series of historical data, then, as already noted, this method too must be vulnerable to small sample bias.

\subsection{Data smoothing}

The problem of potential small sample bias leads to a consideration of whether it is possible to make better use of such limited data. One possibility is to recognise that there are often irregularities in sparse data due to sampling errors, so that it may be useful to smooth them out by fitting a distribution (Schlaifer 1959, Chap. 31; Anderson et al. 1977, pp. 42-44). One way to undertake such smoothing is to use the multivariate kernel density estimation procedure, proposed by Richardson et al. (2006). The procedure is a smoothed multivariate distribution extension of the multivariate empirical (MVE) distribution estimate procedure described by Richardson et al. (2000). The procedure uses a kernel density estimation (KDE) function to smooth the limited sample data of variables in a system individually, and then the dependencies present in the sample are used to model the system via use of a copula. Given a small sample, the choice of copula is more or less confined to the normal, based on correlations calculated from the adjusted sample data or derived subjectively (e.g., Kennedy and Ng 1978; Fackler 1991; Clemen and Reilly 1999). The resulting stochastic simulation procedure is called the multivariate kernel density estimate (MVKDE) of a random vector. The procedure amounts to fitting to the sparse information a generalised multivariate distribution, which then offers the opportunity to simulate as many states as may be judged necessary for incorporation in the programming model.

\section{Method}

\subsection{Overview}

In this paper we applied the MVKDE smoothing method to activity net revenue data applicable to a case farm. After deriving the kernel-smoothed multivariate distribution of per unit activity GMs, we assumed that we have the true joint distribution of per unit GMs to undertake Monte Carlo experiments for the effect of sample size on the results obtained from two alternative risk programming models (i.e., E,V and UE).

The case farm was chosen to reflect the conditions of a typical lowland farm in Eastern Norway. The lowlands of Eastern Norway enjoy geographical, soil and climatic conditions that are more favourable for agriculture than those of other regions of the country. The growing season lasts about 180 days from April/May to September/October. Production possibilities on the case farm are livestock and crops. Quotas and regulations restrict many of the enterprises. The models were programmed to find the optimal farm plans for the coming year by maximising the expected utility of income, directly or via a mean-variance approximation, given the farmer's degree of risk aversion. For ease of interpretation, we evaluated the solutions obtained in terms of certainty equivalents (CEs) of risky income, as explained below.

We examine the planning error from using various numbers of observations and risk programming method by considering the $\mathrm{CE}$ for each plan evaluated over a large number of possible states of nature. By the nature of the inherent uncertainty, we can never be sure what the overall optimal farm plan is, but we can estimate the planning error by comparing this latter CE with the corresponding CEs obtained when the model is solved with a large number of states of nature included. 


\subsection{Utility and certainty equivalent}

Because we assume that the farmer is risk-averse, we are restricted to using a concave form of the utility function with $U^{\prime}(z)>0$, and $U^{\prime \prime}(z)<0$. Although in principle any kind of utility function can be used, we used the negative exponential function:

$$
U(z, r)=1-\exp (-r * z)
$$

where $r$ is a non-negative parameter representing the coefficient of absolute risk aversion with respect to net income, $z$. This function exhibits constant absolute risk aversion (CARA), which is a reasonable approximation to the real but unknown utility function for wealth for variations in transitory (annual) income (Hardaker et al. 2004). We assume that $p_{s}=1 / S$, i.e. that all states of nature are equi-probable. For simplicity, we also assume that the farmer's relative risk aversion with respect to wealth $r_{r}(w)=2$, implying rather strong risk aversion. However, we do not measure utility and risk aversion in terms of wealth, but in terms of transitory income (i.e., a bad or good result in one year has little effect on wealth and hence on income levels in subsequent years). Since we use a negative exponential utility function in terms of transitory income, $z$, we need a relationship between $r_{r}(w)$ and $r$. Assuming asset integration, Hardaker et al. (2004) prove that:

$$
r=r_{r}(w) / w
$$

The level of the farmer's wealth (net assets), $w$, is assumed to be NOK (Norwegian kroner) 2 million, so a value of $r=2 / 2000000=0.000001$ was used as the farmer's degree of absolute risk aversion in this analysis.

We convert the expected utility of net income of any farm plan derived from the UE model to an estimate of $C E$ by taking the inverse of the utility function: ${ }^{1}$

$$
C E(z, r)=-\ln \{1-E[U(z, r)]\} / r
$$

The estimates of CEs are readily interpreted because, unlike utility values, they are expressed in money terms and then make it easy to compare UE results with E,V results.

\subsection{The utility efficient programming model}

The UE model for the case farm was formulated as follows:

$$
\begin{aligned}
& \operatorname{Max} E[U]=p U(z, r), \quad r \text { varied, where } \\
& E[U(z, r)]=\sum_{s} p_{s}\left\{1-\exp \left(-r \times z_{s}\right)\right\}
\end{aligned}
$$

subject to:

$$
\begin{aligned}
A x & \leq b \\
C x+A P x-L F x-I z & =f \\
x & \geq 0
\end{aligned}
$$

\footnotetext{
${ }^{1}$ While the utility function maps income to utility, the inverse function maps utility to income.
} 
where: $E[U]$ is expected utility, $p$ is vector of probabilities for states of nature, $U(z, r)$ is a vector of utilities of net income where the utility function is defined for a parameter that captures risk aversion, $r, A$ is a matrix of technical coefficients, $x$ is a vector of activity levels, $b$ is a vector of resource stocks, $C$ is a matrix of GMs (without public payment schemes) for $S$ states of nature which represents possible realisations of the uncertain activity returns, $A P$ is a matrix of public payment schemes for $S$ states of nature, $L F$ is a matrix of livestock enterprises fodder costs (i.e. the model finds the least-cost supply of feed) for $S$ states of nature, $I$ is a identity matrix, $z$ is a vector of net incomes for each state of nature $S, f$ is a vector of fixed costs.

\subsection{The mean-variance programming model}

Based on the early work of Markowitz (1952), Freund (1956) showed that quadratic risk programming can be used in farm planning to maximise the expected income of a risk-averse decision-maker subject to a set of resource and other constraints including a parametric constraint on the variance of income. The E,V model for the case farm was formulated as follows:

$$
\max C E=E-\frac{r}{2} \cdot V
$$

subject to:

$$
\begin{aligned}
A x & \leq b \\
C x+A P x-L F x-I z & =f \\
x & \geq 0
\end{aligned}
$$

where $C E$ is the certainty equivalent, $E$ is the expected net farm income (with public payment schemes) from implementing a farm plan, $r$ is the absolute risk aversion coefficient (assumed constant), $V$ is the variance of net farm income (random component), and other notation is as defined above for the UE model. As can be seen from previous equations, this restrictively uses the first two moments (i.e. mean and variance) of each risky activity and the first co-moment (i.e. covariance) between the risky activities.

The E,V and UE models were solved using GAMS/CONOPT3.

\subsection{Activities and constraints}

The main activities of the case farm are as follows:

1. Crop activities: barley, oats, wheat, potatoes, oilseed, grass seed and carrots.

2. Livestock activities: dairy cows and sheep.

3. Fodder crop activities: root crops, green fodder and grassland.

4. Concentrate feed activities. Three different types of concentrate feed, with different levels of protein, are included. Animal feed requirements are assumed fixed per head, but choice of feed types is possible.

5. Hire labour and rent land activities. Provision is made to hire labour at the current wage rate of NOK 135 per hour (h). It is assumed that labour can be hired at any time of year. There is also provision to rent in land at NOK 3720 per ha, which is the average cost of renting land in Eastern Norway. 
6. Public payment schemes. The prevailing payment schemes (2004/2005) in Norway are included (NILF 2005). Farmers are paid per livestock head or per ha of crop, with rates varying according to type of livestock or crop. Rates of payments decline with increases in the scale of production.

The main constraints are as follows:

1. Land constraint. A farm size of 20 ha is assumed, which is close to the average farm size in the lowlands of Eastern Norway.

2. Rotational limits. To avoid the build-up of pests and diseases we assume that no more than one-third of the area can be potatoes, and a maximum of one-sixth of the area can be carrots.

3. Marketing limit. Grass seed is regulated by production contracts. Many requirements must be satisfied to get a contract. In this analysis, we restrict grass seed production to 3 ha.

4. Milk quota constraint. The farm's milk quota is set at 100000 litres, which effectively sets an upper limit on the number of dairy cows.

5. Root crop limit. Root crops for fodder are limited to no more than 25 per cent of the coarse fodder produced, measured in terms of livestock feed units. The basis for this constraint is that, as ruminants, cows and sheep need a minimum proportion of coarse fodder in their feed.

6. Seasonal labour constraints. There is one constraint on labour availability in each of the four seasons of spring, summer, autumn and winter. The spring season covers April and May (spring work period). The summer season is June and July, while the autumn period covers August, September and October (harvesting period). The winter season is from November to March. Labour availability is calculated on the basis of one full-time owner operator and one part-time family worker. It is assumed that the maximum amount of family labour available is $3600 \mathrm{~h}$ per year, distributed as $600 \mathrm{~h}$ in the spring and summer seasons, $900 \mathrm{~h}$ in the autumn season and $1500 \mathrm{~h}$ in the winter season. Technical inputoutput coefficients for seasonal labour requirements per unit of the activities are assumed fixed and are based on data from NILF (2005).

7. Hire labour constraint. Family labour may be supplemented with hired labour at times of peak need in the model. The maximum amount of hired labour per year is set at $300 \mathrm{~h}$, since it is sometimes difficult to get qualified farm workers in this area.

8. Rent land constraint. We set a limit of 15 ha on the amount of land that can be rented in. Since many fields are scattered, transport costs tend to increase rapidly with increased hired area. Therefore we estimate that 35 ha, comprising 20 ha of existing land and 15 ha rented, is the maximum area that could be cultivated with the farm's existing machinery.

9. Subsidy constraints. Subsidy constraints are set to reflect the subsidy system that prevailed in 2005 (NILF 2005).

Fixed costs for the case farm are assumed to total NOK 300 000, treated as certain.

\subsection{States of nature data}

To represent the uncertainty in activity GMs (i.e. matrix $V$ in the E,V model in Sect. 3.4 or matrix $C$ in the UE model in Sect. 3.3), we used the method described in Hardaker et al. (2004, pp. 80-82) applied to similar data and a similar farm planning problem as described by Lien and Hardaker (2001).

Historical data from 1996 to 2005 in Eastern Norway in the Norwegian Farm Accountancy Survey were used to estimate the historical variation in activity GMs per unit within 
Table 1 Adjusted historical distribution of activity GMs in $\mathrm{NOK}^{\mathrm{a}}$ per unit by state of nature ${ }^{\mathrm{b}}$

\begin{tabular}{lrrrrrrrrr}
\hline $\begin{array}{l}\text { States } \\
\text { (Year) }\end{array}$ & Barley & Oats & Wheat & Potatoes & Oilseed & Carrots & Grass seed & Dairy cows & Sheep \\
\hline 1996 & 85.9 & 84.3 & 86.8 & 211.6 & 72.5 & 660.1 & 112.2 & 27581 & 841 \\
1997 & 82.4 & 75.8 & 94.5 & 219.4 & 63.8 & 733.4 & 146.9 & 20357 & 913 \\
1998 & 86.0 & 95.1 & 110.3 & 266.6 & 80.4 & 540.3 & 99.8 & 24719 & 682 \\
1999 & 51.2 & 73.9 & 67.1 & 362.2 & 61.2 & 568.1 & 123.1 & 20572 & 279 \\
2000 & 48.2 & 47.8 & 85.3 & 239.0 & 46.0 & 532.7 & 74.0 & 15636 & 858 \\
2001 & 64.9 & 54.6 & 37.7 & 247.5 & 56.7 & 477.4 & 122.8 & 16828 & 760 \\
2002 & 51.0 & 44.0 & 48.8 & 225.9 & 57.4 & 533.1 & 97.4 & 23181 & 685 \\
2003 & 66.0 & 87.4 & 85.3 & 346.3 & 74.4 & 442.8 & 70.8 & 19434 & 811 \\
2004 & 108.7 & 116.4 & 111.2 & 353.9 & 43.5 & 1190.0 & 75.3 & 22845 & 649 \\
2005 & 74.8 & 66.2 & 99.1 & 107.1 & 91.7 & 377.0 & 187.1 & 27581 & 851 \\
Mean & 71.9 & 74.6 & 82.6 & 258.0 & 64.8 & 605.5 & 111.0 & 21873 & 733 \\
SD & 19.4 & 22.5 & 24.6 & 78.8 & 15.1 & 229.1 & 36.4 & 4085 & 182 \\
\hline
\end{tabular}

${ }^{\mathrm{a}} 1 \mathrm{NOK}=0.124$ EUR per 1 . January 2008

${ }^{\mathrm{b}}$ Barley, oats, wheat, potatoes, oilseed, grass seed and carrots are per hectare. Dairy cow and sheep are per head

${ }^{\mathrm{c}} \mathrm{SD}=$ standard deviation

farms between years. The consumer price index was used to bring the individual enterprises to 2005-money values. From the farm-level, historical unbalanced panel data we derived a de-trended enterprise GM per unit matrix, representative for one single farm. Assuming that the historical data are not fully relevant for the future, the derived matrix for the individual farm was combined with subjective judgments about the marginal distributions of the individual activity GMs. The reconstructed series has the subjectively elicited means and standard deviations while preserving the general shapes of the marginal distributions and the correlation and other stochastic dependencies embodied in the historical data. The numbers derived are shown in Table 1, and these enterprise GMs constitute the states of nature matrix that was the starting point for our analysis of risk representation for farm planning.

The data were fitted to a smoothed generalised multivariate distribution using the MVKDE procedure outlined above and described by Richardson et al. (2006). The procedure calls for estimating the parameters for a kernel distribution to the GM of each activity. The resulting continuous probability distribution for each random variable smoothed out the irregularities caused by small samples. Correlations between activity net revenues were derived directly from the historical data and used to simulate the kernel distributions as a multivariate distribution using the MVE procedure described by Richardson et al. (2000).

The rest of the analysis was based on the pretence that this smoothed distribution was the one from which Nature samples realised adjusted historical or future outcomes.

\subsection{Computations}

Samples of predetermined sizes were drawn from the assumed known distribution to reflect what might have been the recent history upon which the risk programming model could have been based. To keep the experiment feasible, the programming models were solved with sample sizes of 5, 15, 20,30,50,100, and 200, each with eight replicates, and a sample 
size of 10 with 100 replicates. The latter sample size is of special interest because for farm planning purposes it is generally hard to obtain more than 10 relevant observations under the same economic policy, management regime, farm program or trade policy. The increased number of replicates enabled a more in-depth analysis between results obtained from $\mathrm{E}, \mathrm{V}$ and UE.

For each obtained programming solution, we evaluated the CE of net income that could be expected ex ante from that solution using stochastic simulation with 500 replicates, drawn from the same MVKDE smoothed distribution but sampled with the Latin hypercube algorithm in order to improve convergence. Thus, the simulated CEs of net income reported are generally different from those obtained from the E,V and UE programming results because they are based on a large sample of possible GM realisations drawn from the assumed known distribution of possible states.

\section{Results}

The variability of the farm plan solutions obtained with UE is illustrated in Table 2, for a subset of the results with 5, 10, 50 and 200 states of nature.

It is clear from these results that, for the UE model of this farm situation, models with few states may give quite variable farm plans, depending on the chance occurrence of past events upon which the states of nature matrix is constructed. Moreover, although the variability in activity levels obtained in the optimal farm plans can be seen to decrease with increasing number of states of nature, even with as large a number as 200 states, the results are not completely stabilised.

Of course, solutions with quite different activity mixes may yield rather similar values for the objective function (Pannell 2006), so that getting the farm plan 'right' may be relatively unimportant, within limits. The consequences of the choice of sub-optimal farm plans based on the UE model are explored in Fig. 1, which shows the mean and scatter of simulated CEs for the plans derived for different numbers of states of nature. The highest recorded CE of net income, which may be assumed to be the strict optimum, was NOK 239402 . With only five states, three out of the eight solutions gave CE values of less than NOK 222085 , implying a loss of income of $7 \%$ or more. The worst plan found, with only 5 states of nature, yielded a CE of net income $10 \%$ below the best. None of the 24 solutions with 5, 10 or 15 states of nature included the optimum optimorum.

Using E,V programming similar conclusions were drawn. Simulated results for CE of net income also showed appreciable differences between solutions even with unrealistically large sample sizes, entailing considerable reduction in CEs. While it is not safe to put much emphasis on averages based on only eight replicates (either from E,V or UE), it is clear that the mean error in CE of the derived plans falls as the number of observations is expanded and that this error is still declining even at the upper limit of sample size examined.

The above results illustrate that, when data for specifying risk in farm planning models are sparse, as will usually be the case, the solutions can be unreliable. Subsequently, the outcomes derived with UE and E,V programming are compared under the situations whereby identical input information is used (being either the states of nature for UE or the mean and the variance-covariance matrix derived from it for $\mathrm{E}, \mathrm{V}$ ). The maximum absolute differences between $\mathrm{E}, \mathrm{V}$ and $\mathrm{UE}$ in levels of activities in solution farm plans between replicates are presented in Table 3.

Comparing the results with respect to the optimal farm plan showed that there are few differences between the two and the differences which do occur are mainly trivial if identical 
Table 2 Farm plans, based on UE, for 5, 10, 50 and 200 simulated number of states of nature

\begin{tabular}{|c|c|c|c|c|c|c|c|c|c|}
\hline $\begin{array}{l}\text { States of } \\
\text { nature } \\
\text { no. }\end{array}$ & $\begin{array}{l}\text { Barley } \\
\text { ha }\end{array}$ & $\begin{array}{l}\text { Oats } \\
\text { ha }\end{array}$ & $\begin{array}{l}\text { Wheat } \\
\text { ha }\end{array}$ & $\begin{array}{l}\text { Potatoes } \\
\text { ha }\end{array}$ & $\begin{array}{l}\text { Oilseed } \\
\text { ha }\end{array}$ & $\begin{array}{l}\text { Carrot } \\
\text { ha }\end{array}$ & $\begin{array}{l}\text { Grass seed } \\
\text { ha }\end{array}$ & $\begin{array}{l}\text { Dairy } \\
\text { cows } \\
\text { no. }\end{array}$ & $\begin{array}{l}\text { Sheep } \\
\text { no. }\end{array}$ \\
\hline 5 & 16.2 & & & & & 1.8 & 3.0 & 16.0 & 13.7 \\
\hline 5 & & 15.0 & & & & 2.0 & 3.0 & 16.0 & 13.7 \\
\hline 5 & & & 15.3 & & & 1.7 & 3.0 & 16.0 & 13.7 \\
\hline 5 & & & & & 19.6 & 2.1 & 3.0 & 9.1 & 75.0 \\
\hline 5 & 23.3 & & & 1.5 & & 4.7 & 3.0 & 2.8 & \\
\hline 5 & & 18.4 & & & & 3.3 & 3.0 & 11.6 & \\
\hline 5 & & 23.3 & & 1.3 & & 4.5 & 3.0 & 0.3 & 42.2 \\
\hline 5 & & 21.9 & & 0.7 & & 3.6 & 3.0 & 8.0 & \\
\hline 10 & 17.7 & & & & & 2.6 & 3.0 & 8.1 & 75.0 \\
\hline 10 & 22.4 & & & 0.9 & & 4.1 & 3.0 & & 75.0 \\
\hline 10 & 20.1 & & & & & 2.3 & 3.0 & 8.1 & 75.0 \\
\hline 10 & 16.2 & & & & & 1.8 & 3.0 & 16.0 & 13.7 \\
\hline 10 & & 15.6 & & & & 2.3 & 3.0 & 16.0 & \\
\hline 10 & & & 19.5 & & & 2.8 & 3.0 & 5.8 & 75.0 \\
\hline 10 & & 1.1 & 22.2 & 1.7 & 1.0 & 4.3 & 3.0 & & 28.5 \\
\hline 10 & & & 23.2 & 1.4 & & 4.1 & 3.0 & 3.8 & \\
\hline 50 & & 19.4 & & & & 3.3 & 3.0 & 5.4 & 75.0 \\
\hline 50 & & 18.7 & & & & 3.0 & 3.0 & 6.5 & 75.0 \\
\hline 50 & & 15.0 & & & & 2.0 & 3.0 & 16.0 & 13.7 \\
\hline 50 & & 7.9 & 11.6 & & & 3.0 & 3.0 & 5.6 & 75.0 \\
\hline 50 & & 16.4 & & & & 2.3 & 3.0 & 12.0 & 44.7 \\
\hline 50 & & 11.9 & 3.1 & & & 2.0 & 3.0 & 16.0 & 13.7 \\
\hline 50 & & 18.7 & & & & 3.0 & 3.0 & 6.5 & 75.0 \\
\hline 50 & & & 19.5 & & & 2.8 & 3.0 & 5.8 & 75.0 \\
\hline 200 & & & 18.0 & & & 2.3 & 3.0 & 8.1 & 75.0 \\
\hline 200 & & 18.7 & & & & 3.0 & 3.0 & 6.5 & 75.0 \\
\hline 200 & & 17.7 & & & & 2.6 & 3.0 & 8.1 & 75.0 \\
\hline 200 & & 18.7 & & & & 3.0 & 3.0 & 6.5 & 75.0 \\
\hline 200 & & 17.6 & & & & 3.0 & 3.0 & 12.9 & \\
\hline 200 & & 17.7 & & & & 2.6 & 3.0 & 8.1 & 75.0 \\
\hline 200 & & 17.7 & & & & 2.7 & 3.0 & 8.0 & 75.0 \\
\hline 200 & & 17.7 & & & & 2.7 & 3.0 & 8.0 & 75.0 \\
\hline
\end{tabular}

input information is used. With increases in number of states (to unrealistic high number of states of nature) differences become even smaller.

The E,V and UE results obtained from the in-depth analysis with 100 replications are presented in Fig. 2. Sample size was set at 10 which is of special interest because for farm planning purposes it is generally hard to obtain more than 10 observations. Pair-wise differences are determined again under the assumption that identical input information is used for both models. The cumulative probability distribution for $\mathrm{CE}$ of net income showed a 


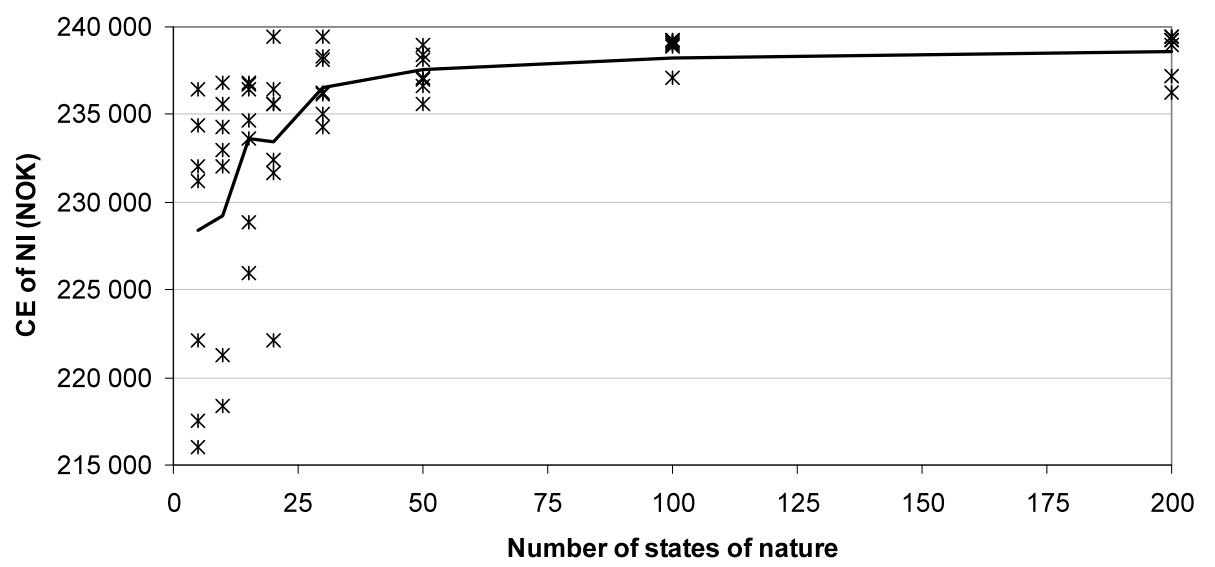

Fig. 1 Simulated results for CE of net income (NI), based on UE with states of nature between 5 and 200

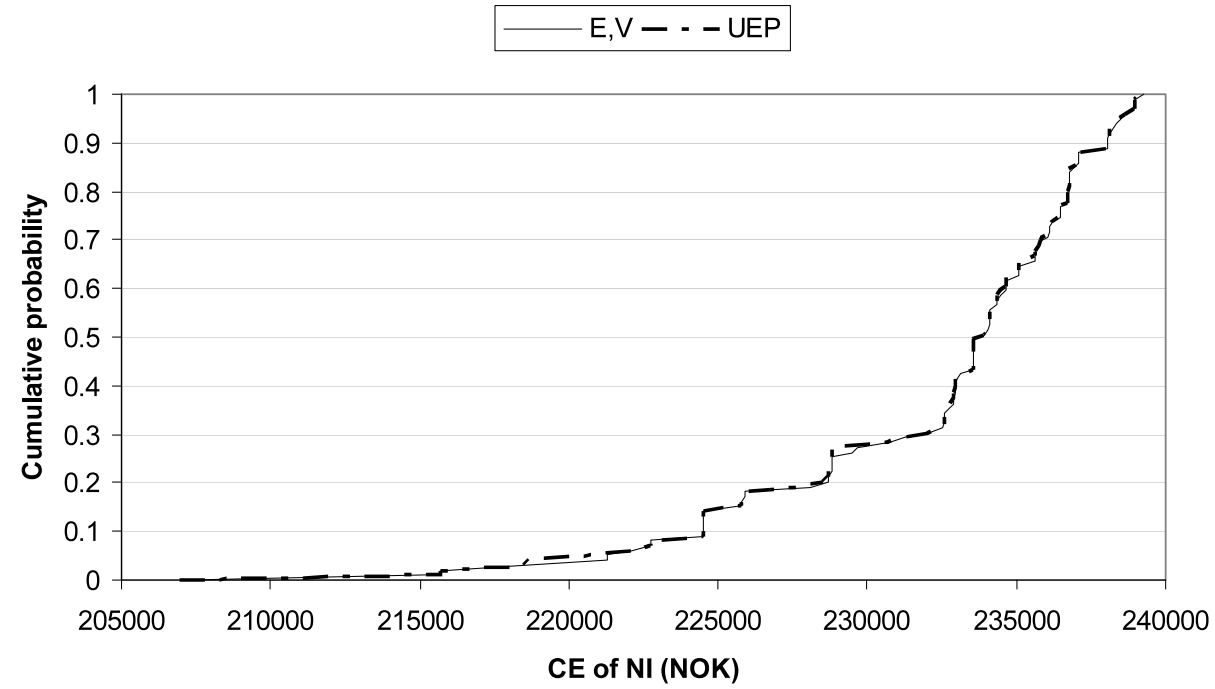

Fig. 2 Cumulative probability distribution based on 100 replicates for CE of net income (NI) for E,V and $\mathrm{UE}$ and 10 states of nature

Table 3 Maximum absolute differences between E,V and UE in levels of activities in solution farm plans between replicates with increases in the number of states of nature

\begin{tabular}{llllll}
\hline No. states: & \multicolumn{2}{l}{5} & 10 & 50 & 200 \\
\hline Barley & ha & 0.00 & 0.00 & 0.00 & 0.00 \\
Oats & ha & 0.03 & 0.38 & 0.42 & 0.00 \\
Wheat & ha & 0.00 & 0.17 & 0.43 & 0.00 \\
Potatoes & ha & 0.17 & 0.05 & 0.00 & 0.00 \\
Oilseed & ha & 0.00 & 0.05 & 0.00 & 0.00 \\
Carrots & ha & 0.18 & 0.04 & 0.02 & 0.00 \\
Grass seed & ha & 0.0 & 0.00 & 0.00 & 0.00 \\
Dairy cows & no. & 2.5 & 0.1 & 0.3 & 0.0 \\
Sheep & no. & 42.2 & 1.4 & 2.1 & 0.0 \\
\hline
\end{tabular}


high risk of generating appreciably sub-optimal solutions for both approaches. For example, there is a $27 \%$ chance of a chosen production plan resulting in a net income of less than NOK 230000 . Moreover, neither of the two methods was consistently superior, otherwise one of the two lines would be more often to the right (one method would be dominating if with the same cumulative probability a better production plan could be found that generated a higher net farm income).

\section{Discussion and conclusions}

It is difficult to draw precise and definitive conclusions from this Monte Carlo analysis of the number of observation in risk programming models because we used one specific model with one particular data set. Such explorations for other farm planning tasks would be needed to assess the generality of the size of effects we have demonstrated. However, it is clear that reliance on just a few activity net revenue states derived from a short sequence of recent historical records entails a considerable risk of generating misleading results, perhaps seriously so. Moreover, comparing the E,V results with the UE results showed that there were few discrepancies between the two methods and the differences which do occur are mainly trivial. So selecting an alternative risk programming method will not improve the outcomes. It follows that, while few states of nature can give misleading results when evaluating the central part of a distribution (e.g., income), the approximation error is likely to be even higher when dealing with the tails of the distribution, as when evaluating the effects of stabilization tools such as crop insurance. We conclude that the 'few states' problem matters in advising individual farmers and in analysing case study or representative farms for some policy purposes.

Our results imply that analysts need to give much more thought than seems to have been the case in the past, by estimating multivariate probability functions that provide good descriptions of the risk faced in the planning period. While it is likely that these descriptions will continue to be partly based on historical data, there is a clear need to use other information and judgments to improve confidence in the programming results.

Open Access This article is distributed under the terms of the Creative Commons Attribution Noncommercial License which permits any noncommercial use, distribution, and reproduction in any medium, provided the original author(s) and source are credited.

\section{References}

Ames, G. C. W., Reid, D. W., \& Hsiou, L. F. (1993). Risk analysis of new maize technology in Zaire: a portfolio approach. Agricultural Economics, 9, 203-214.

Anderson, J. R., Dillon, J. L., \& Hardaker, J. B. (1977). Agricultural decision analysis. Ames: Iowa State University Press.

Atwood, J., Shaik, S., \& Watts, M. (2003). Are crop yields normally distributed? A re-examination. American Journal of Agricultural Economics, 85, 888-901.

Bhende, M. J., \& Venkataram, J. V. (1994). Impact of diversification on household income and risk: a wholefarm modelling approach. Agricultural Systems, 44, 301-312.

Chalfant, J. A., Collender, R. N., \& Subramanian, S. (1990). The mean and variance of the mean-variance decision rule. American Journal of Agricultural Economics, 72, 966-974.

Clemen, R. T., \& Reilly, T. (1999). Correlation and copulas for decision and risk analysis. Management Science, 45, 208-224.

Collender, R. N. (1989). Estimation risk in farm planning under uncertainty. American Journal of Agricultural Economics, 71, 996-1002. 
Dorward, A. (1999). A risk programming approach for analysing contractual choice in the presence of transaction costs. European Review of Agriculture Economics, 26, 479-492.

Epplin, F. M., \& Al-Sakkaf, G. A. (1995). Risk-efficient tillage systems and program participation strategies for land subject to conservation compliance. Review of Agricultural Economics, 17, 311-321.

Fackler, P. L. (1991). Modeling interdependence: an approach to simulation and elicitation. American Journal of Agricultural Economics, 73, 1091-1097.

Flaten, O., \& Lien, G. (2007). Stochastic utility-efficient programming of organic dairy farms. European Journal of Operational Research, 181, 1574-1583.

Freund, R. J. (1956). The introduction of risk into a programming model. Econometrica, 24, 253-263.

Hardaker, J. B., Huirne, R. B. M., Anderson, J. R., \& Lien, G. (2004). Coping with risk in agriculture, 2nd edn. Wallingford: CABI Publishing.

Hardaker, J. B., Lien, G., \& Richardson, J. W. (2007). Expanding the states of nature for risk programming. Contributed paper to the Australian Agricultural and Resource Economics Society's 51st Annual Conference, Queenstown, New Zealand, February 13-15, 2007.

Hazell, P. B. R. (1971). A linear alternative to quadratic and semivariance programming or farm planning under uncertainty. American Journal of Agricultural Economics, 53, 53-62.

Just, R. E., \& Weninger, Q. (1999). Are crop yields normally distributed? American Journal of Agricultural Economics, 81, 287-304.

Kennedy, J. O. S., \& Ng, G. P. (1978). Alternative measures of variance in risk programming models. European Review of Agricultural Economics, 5, 5-20.

Kobzar, O. A., van Asseldonk, M. A. P. M., \& Huirne, R. B. M. (2005). Whole-farm planning under risk: Application of alternative risk programming techniques to support portfolio decisions in Dutch agriculture. In Agricultural economics society annual conference, University of Nottingham, England.

Krause, M. A., Deuson, R. R., Baker, T. G., Preckel, P. V., Lowenberg-DeBoer, J., Reddy, K. C., \& Maliki, K. (1990). Risk sharing versus low-cost credit systems for international development. American Journal of Agricultural Economics, 72, 911-922.

Lambert, D. K., \& McCarl, B. A. (1985). Risk modeling using direct solution of nonlinear approximations of the utility function. American Journal of Agricultural Economics, 67, 846-852.

Lence, S. H., \& Hayes, D. J. (1995). Land allocation in the presence of estimation risk. Journal of Agricultural and Resource Economics, 20, 49-63.

Lien, G., \& Hardaker, J. B. (2001). Whole-farm planning under uncertainty: impacts of subsidy scheme and utility function on portfolio choice in Norwegian agriculture. European Review of Agricultural Economics, 28, 17-36.

Markowitz, H. (1952). Portfolio selection. Journal of Finance, 7, 77-91.

NILF (2005). Handbok for driftsplanlegging [Handbook in farm business planning] 2005/2006. Oslo: Norwegian Agricultural Economics Research Institute.

Olson, K. D., \& Eidman, V. R. (1992). A farmer's choice of weed control method and the impacts of policy and risk. Review of Agricultural Economics, 14, 125-137.

Pannell, D. J. (2006). Flat earth economics: The far-reaching consequences of flat payoff functions in economic decision making. Review of Agricultural Economics, 28, 553-566.

Pannell, D. J., \& Nordblom, T. J. (1998). Impacts of risk aversion on whole-farm management in Syria. Australian Journal of Agricultural and Resource Economics, 42, 227-247.

Patten, L. H., Hardaker, J. B., \& Pannell, D. J. (1988). Utility-efficient programming for whole-farm planning. Australian Journal of Agricultural Economics, 32, 88-97.

Richardson, J. W., Klose, S. L., \& Gray, A. W. (2000). An applied procedure for estimating and simulating multivariate empirical (MVE) probability distributions in farm-level risk assessment and policy analysis. Journal of Agricultural and Applied Economics, 32, 299-315.

Richardson, J. W., Lien, G., \& Hardaker, J. B. (2006). Simulating multivariate distributions with sparse data: a kernel density smoothing procedure. Poster paper contributed to the 26th International Conference of Agricultural Economics, Gold Cost, Australia, August 12-18, 2006.

Romero, C. (2000). Risk programming for agricultural resource allocation: a multidimensional risk approach. Annals of Operations Research, 94, 57-68.

Schlaifer, R. (1959). Probability and statistics for business decisions. New York: McGraw-Hill.

Tauer, L. W. (1983). Target MOTAD. American Journal of Agricultural Economics, 65, 608-610.

Torkamani, J. (2005). Using a whole-farm modelling approach to assess prospective technologies under uncertainty. Agricultural Systems, 85, 138-154. 